\title{
WHEN WORDS SPEAK LOUDER THAN ACTIONS: DELUSION, BELIEF AND THE POWER OF ASSERTION
}

\author{
David Rose, Wesley Buckwalter and John Turri
}

People suffering from severe monothematic delusions, such as Capgras, Fregoli or Cotard patients, regularly assert extraordinary and unlikely things. For example, some say that their loved ones have been replaced by impostors. A popular view in philosophy and cognitive science is that such monothematic delusions aren't beliefs because they don't guide behavior and affect in the way that beliefs do. Or, if they are beliefs, they are somehow anomalous, atypical, or marginal beliefs. We present evidence from five studies that folk psychology unambiguously views monothematic delusions as stereotypical beliefs. This calls into question widespread assumptions in the professional literature about belief's stereotypical functional profile. We also show that folk psychology views delusional patients as holding contradictory beliefs. And we also show that frequent assertion is a powerful cue to belief-ascription, more powerful than even a robust and consistent track record of non-verbal behavior.

Keywords: delusion, belief, folk psychology, assertion

\section{A Question of Attitude: Are Delusions Beliefs?}

In their work on clinical subjects, Hirstein and Ramachandran [1997] present the case of a patient named DS. DS was a middle-aged man who suffered a traumatic brain injury in a 
gruesome traffic accident. In the year following his injury he began what appeared to be a remarkable and speedy recovery. DS regained his powers of speech, intelligence, as well as nearly all his cognitive and social skills. However there was something very strange about DS after his accident. He would regularly tell his doctors, family, and friends that his parents had been replaced by imposters.

DS was later diagnosed with a condition called Capgras Syndrome, a rare neurological disorder where patients suffer the delusion that someone close to them - such as a loved one, family member, or friend - has been replaced by a duplicate or imposter. Typical of Capgras patients, when others confront DS with putative evidence that his parents are not actually imposters, his assertions to the contrary persist. ${ }^{1}$ In the words of DS when interviewed by Hirstein and Ramachandran, “He looks exactly like my father but he really isn't. He's a nice guy, but he isn't my father, Doctor" [p. 438].

As is also typical of patients with Capgras Syndrome, despite DS's assertions, he doesn't exhibit the stereotypical non-verbal behaviors we would normally expect if he believed that these people are impostors. Capgras patients typically continue to share their lives with the purported imposters. The presence of these "intruders" is not typically reported to the police. Nor does the syndrome typically lead to flight or violent outbursts of behavior.

These striking features of Capgras syndrome raise an interesting question: what does DS believe about his parents? On the one hand, DS regularly says that impostors have replaced his

${ }^{1}$ This work corroborates earlier findings by Alexander, Stuss and Benson [1979: 335] showing that patients may continue to hold such attitudes while simultaneously appreciating the implausibility of the story and the incredulity of others. 
parents. On the basis of his verbal behavior, you might naturally conclude that DS believes that his parents are impostors. On the other hand, there is DS's wider range of non-verbal behavior, which doesn't cohere with what he says about his parents being replaced. He does not run away from these imposters; he does not call the police; he doesn't seek out lost loved ones. On the basis of these non-verbal behaviors, you might naturally conclude that DS believes his parents are really who they say they are.

Many philosophers and cognitive scientists resist ascribing to DS the belief that his parents are impostors. These theorists assume that belief has essential properties which DS's delusional attitude lacks. First, beliefs are responsive to evidence, but DS's delusional attitudes aren't. Second, beliefs lead predictably to further beliefs and to behavior that make sense in light of them, whereas DS's overall behavior doesn't seem to make sense in light of the delusional attitudes and his desires. One assumes, for example, that DS doesn't want to live with impostors and wants to reconnect with the purportedly missing loved ones. Third, beliefs lead predictably to affective responses that make sense in light of them, whereas DS doesn't exhibit such responses. He is neither shocked, horrified, nor deeply saddened at the purported fact that impostors replaced his loved ones. Yet these are feelings that we would naturally expect if the delusional attitudes were genuine beliefs. In sum, delusional attitudes like DS's "fail to play the functional role that is essential to a state's being a belief" [Bayne 2010: 330]. They are far too inferentially, behaviorally, and affectively circumscribed to be beliefs.

Of course this raises an obvious question: what are these attitudes, then? Some say they belong to some other familiar folk-psychological categories, such as imagination [Currie 2000; Currie and Jureidini 2001; Currie and Ravenscroft 2002], pretense [Gendler 2007], or illusion 
[Hohwy and Rajan 2012]. Others argue that no familiar folk-psychological category fits the bill, which motivates them to invent new categories, such as "bimagination" [Egan 2009], a hybrid of belief and imagination that incorporates stereotypical elements of both. And even those who defend the "doxasticist" view that delusional attitudes are beliefs say that delusions are "anomalous" beliefs [Bortolotti 2012; Bortolotti and Mameli 2012], or that they are beliefs in some contexts but not others [Reimer 2010]. Still others hold that they aren't "fully" beliefs because they don't "fully meet any relevant folk-psychological stereotype" for belief [Tumulty 2012: 30, n. 2; see also Schwitzgebel 2011; Schwitzgebel 2001].

Note well that even those who defend the view that delusions are (at least partly) beliefs agree that these attitudes "deviate" from "the causal-functional patterns in behavior and cognition characteristic of belief," in which case "the assumptions inherent in the practice of belief ascription start to break down." We're then left with a choice: "either abandon belief talk or allow for some indeterminacy in it" [Schwitzgebel 2011: 16].

We question the widespread assumption that delusional attitudes, such as DS's, are not viewed straightforwardly as beliefs [see, e.g., Bortolotti 2012; Bortolotti and Mameli 2012; Frankish 2012; Murphy 2012; Egan 2009; Schwitzgebel 2001; Schwitzgebel 2011; Tumulty 2012]. Instead of casting about for categories other than belief in which to place such attitudes, or gerrymandering new categories, or offering elaborate theoretical defenses for categorizing them as beliefs, we propose a disarmingly simple and unsophisticated thesis: in cases like DS's, the delusional attitudes are stereotypical beliefs. There is no need to innovate, compromise or apologize. Furthermore, we embrace a corollary of this thesis, namely, that theorists should revise their views about stereotypical belief. Philosophers of mind and cognitive scientists have 
strayed very far indeed from the folk psychology of belief.

This paper presents experimental evidence supporting our thesis and its corollary. More specifically, we accomplish three main things. First, using different measures, we show that the folk readily classify Capgras delusions as beliefs. Second, we show that people view these delusions as beliefs because frequent assertion is a powerful cue to belief ascription. In folk psychology, frequent assertion just is a behavioral pattern stereotypical of belief. Third, delusional patients are readily viewed as holding contradictory beliefs, which can explain the ambivalence we feel when considering such cases.

Before presenting our studies, we want to dispel any appearance that our thesis is somehow radical or revisionary and, thus, that we bear an especially demanding burden of proof. We think that belief is the natural first candidate for categorizing delusions. In fact, clinical psychologists and psychiatrists define delusions as beliefs. The DSM-IV defines 'delusion' as:

\begin{abstract}
A false belief based on incorrect inference about external reality that is firmly sustained despite what almost everyone else believes and despite what constitutes incontrovertible and obvious proof or evidence to the contrary [2000: 765].
\end{abstract}

There is much to criticize in this definition. First, it can't be definitive of delusions that they are false. Second, it can't be definitive of delusions that they are inferential. Third, it can't be definitive of delusion that it be subject to incontrovertible counterevidence. ${ }^{2}$ However, although we're aware of this definition's serious deficiencies, we don't think its basic motivation

\footnotetext{
${ }^{2}$ For extended criticism of the DSM-IV definition of delusions, see Coltheart 2007.
} 
is deficient. Instead, we think it's on the right track. We doubt it's an accident that professionals who deal most closely with delusional patients choose to define delusion as belief. ${ }^{3}$ As we will now proceed to argue, philosophers and cognitive scientists tempted to characterize delusional attitudes as beliefs have been right from the start.

Although we present evidence that folk psychology readily characterizes delusional attitudes as belief, things could have turned out otherwise. It could have turned out that the folk readily deny or are ambivalent about ascribing beliefs to delusional subjects. Had it turned out that way, it would have provided strong evidence that philosophers and cognitive scientists were right to deny that delusional attitudes are viewed as beliefs, or at least as clear cases of belief.

\section{Experiment 1: Robust Belief-ascription to Capgras patients}

This first experiment provides evidence that people view Capgras delusions as beliefs. It also provides evidence that significant behavioral circumscription is consistent with the profile of stereotypical belief.

\subsection{Method}

Participants $(\mathrm{N}=121)^{4}$ were randomly assigned to one of six conditions in a 2 (Action Profile:

${ }^{3}$ For notable exceptions, see Jaspers 1963, and more recently, Parnas 2004, Cermolacce, Sass and Parnas 2010.

4 Forty-one female, aged 18-71, $M=30.19, S D=10.78 ; 93 \%$ reported English as a native language. As with the experiment reported below, participants were U.S. residents recruited using Amazon Mechanical Turk, tested online using Qualtrics survey software, and compensated $\$ 0.30$ for approximately 2 minutes of their 
Typical, Atypical) $\times 2$ (Probe: Thinks, Believes) between-subjects design. All participants read a basic story describing a typical case of Capgras syndrome:

Don and Katherine had been married for ten years. Like most married couples, they spent a lot of time together and did many things together. They regularly shared meals, went to the movies, lived in the same house, and slept in the same bed. Then one day, as Don was driving to the store, a car ran a stop-light, hitting the driver side door of his car. Don suffered a traumatic brain injury as the result of the gruesome traffic accident. $\Upsilon^{5}$ In the year following his injury, he began what appeared to be a remarkable and speedy recovery. Don regained his powers of speech, intelligence, as well as nearly all his cognitive and social skills. However there was something very strange about Don after his accident: he would tell his friends, family and doctors that his wife, Katherine, had been replaced by an imposter. 9

Participants in Typical conditions read a conclusion to the story in which the protagonist, in typical Capgras fashion, continued to treat his partner as he did before his accident and as partners typically treat one another:

time. Participants were not allowed to re-take any survey reported here, and participants who had taken previous similar surveys were excluded by their AMT Worker ID. They filled out a brief demographic survey after testing. Four participants were removed for failing the comprehension question. Including these participants doesn't change the pattern of results reported below. The same is true in all other studies reported here.

5 Indicates a paragraph break on the participant's screen. 
Typical. Katherine was very surprised and saddened by the things Don would say. At the same time, Don continued to always eat meals with her, go to the movies with her, live in the same house as her, and sleep in the same bed as her.

Participants in Atypical conditions read a conclusion to the story in which the protagonist treats his partner as we might expect him to treat an impostor and intruder:

Atypical. Katherine was very surprised and saddened by the things Don would say. At the same time, Don now always refused to eat meals with her, go to the movies with her, live in the same house as her, and sleep in the same bed as her.

We included the Typical/Atypical manipulation in order to determine whether the delusion's behavioral circumscription affects rates of belief ascription. That is, we wanted to know whether people's view of the case changes when the protagonist goes from not acting in a way that coheres with the delusion's content, to acting in a way that coheres with it. The typical Capgras patient does not act consistently with the delusion's content, but unless we manipulate this factor, we can't be confident how behavioral circumscription affects the way people view the case. It is almost universally assumed in the literature that behavioral circumscription counts against classifying delusion as a belief. Will this assumption withstand empirical scrutiny?

After reading the story, all participants were asked a comprehension question to make sure they understood the protagonist's behavioral profile:

Comprehension. After the accident, Don eats, sleeps and spends time with 
Katherine.

Prior work in experimental philosophy and cognitive science has demonstrated two ways to effectively probe belief judgments in folk psychology, the first by asking what a participant "believes is true", the other, what a participant "thinks on some level is true" [Rose and Schaffer 2013; Buckwalter, Rose and Turri 2013; Buckwalter and Turri 2014]. Moreover, predominate experimental work in developmental psychology, including for instance, most studies conducted on the false belief task, evaluate belief ascription by asking what a participant "thinks" is true [see, for instance, Wimmer and Perner 1983; Roth and Leslie 1991]. Guided by this prior research probing belief in folk-psychology, and in order to ensure that our results were not due to peculiarities associated with any one way of probing for belief ascription, participants were asked one of two questions. Participants in Believes conditions were asked about what the protagonist believes. Participants in Thinks conditions were asked about what the protagonist thinks. The two probes were:

Believes. Does Don believe that Katherine is an imposter? (Yes/No)

Thinks. At least on some level, does Don think that Katherine is an imposter? $(\mathrm{Yes} / \mathrm{No})$

\subsection{Results}

We're interested in two questions. First, does folk psychology recognize monothematic delusions of Capgras patients as stereotypical beliefs? If folk psychology does not recognize Capgras 
delusions as stereotypical beliefs, then we should not observe high rates of belief ascription. Instead, rates should be either low or at chance. If this is the case, then this would support the view that Capgras delusions are not instances of stereotypical belief. By contrast, if rates of belief ascription are high, then that supports the view that folk psychology recognizes Capgras delusions as stereotypical beliefs. Second, does behavioral circumscription significantly affect whether Capgras delusions are viewed as beliefs? If it does, then we should observe significantly lower rates of belief ascription in Typical cases than in Atypical cases. And if this were the case, it would go some way toward supporting an account of why cases of Capgras delusion are not instances of stereotypical belief.

The results clearly answer both questions. First, rates of belief ascription were at or near ceiling in all four conditions. On both ways of probing for belief and regardless of behavioral circumscription, participants ascribe belief at rates far exceeding chance: $90-100 \%$, binomial tests, all ps $\leq .0005$, all tests two-tailed unless otherwise noted. Capgras delusions are viewed as stereotypical beliefs.

Second, there was no effect of Action Profile, either for Believes conditions, Fisher's exact test, $p=.237$, or Thinks conditions, Fisher's exact test, $p=1 .^{6}$ The severe behavioral circumscription in Typical conditions did not prevent people from overwhelmingly agreeing that Capgras delusions are beliefs. Surprisingly, and against conventional wisdom, behavioral circumscription had no effect on whether the folk viewed the Capgras patient as having the belief

\footnotetext{
${ }^{6}$ Fisher's exact test is a statistical significance test that is used for categorical data. It is primarily employed when the count within cells in a contingency table is less than 5 . When cells in a contingency table are greater than or equal to 5 and the sample size is decently large, a chi-square $\left(\chi^{2}\right)$ is appropriate [see e.g., fn. 12].
} 
that his wife is an imposter. Figure 1 visualizes these results.

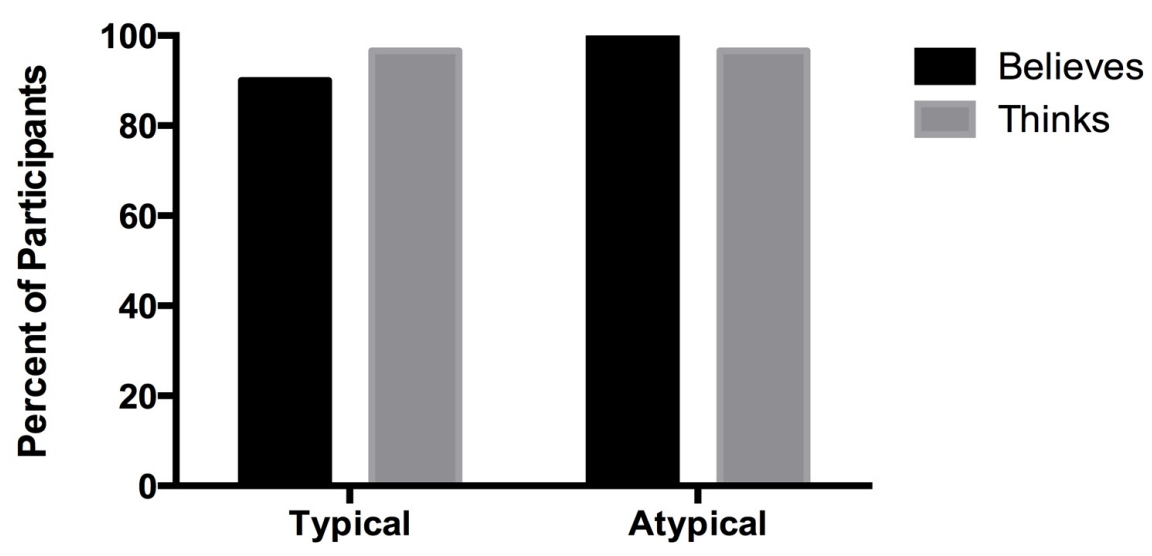

Fig. 1: Experiment 1. Mean response to the test statement that the protagonist "thinks" or "believes" that his wife is an imposter.

\subsection{Discussion}

Belief was nearly unanimously ascribed despite significant behavioral circumscription in Capgras cases. Had participants failed to unanimously ascribe belief, or had significant behavioral circumscription impacted ordinary judgments, this would have supported the claim that delusional attitude is not best characterized in terms of stereotypical belief. However, our results suggest that folk psychology recognizes cases of monothematic delusion as clear and uncontroversial instances of belief. The question we are now faced with is why folk psychology treats monothematic delusions this way. We take this up in the experiments that follow. 


\section{Experiment 2: Assertion and Contradiction}

Some writers have speculated that a Capgras patient's willingness to assert the delusional content is "prima facie evidence for supposing that" they believe the delusional content [Reimer 2010: 325-6]. Moreover, it has recently been shown experimentally that, on some ways of measuring belief-ascription, belief-ascription rises dramatically when the protagonist verbally endorses a target proposition [Buckwalter, Rose and Turri 2013]. Indeed, this work has suggested that assertion can make the difference between attributing and denying belief.

Some writers have also speculated that there might be significant continuity between cases of self-deception and delusions [e.g., Bortolotti and Mameli 2012], while others have denied that there is any significant continuity [e.g., Murphy 2012]. On a standard view of selfdeception [e.g., Davidson 1982, 1986], the self-deceived agent possesses two contradictory beliefs that are compartmentalized or partitioned. If this characterization of self-deception is correct and if one suspects that there is considerable overlap between cases of self-deception and delusion, then could it be that delusional patients are viewed as holding contradictory beliefs? For instance, could it be that Don both believes that Katherine is his wife and believes that Katherine is an impostor? Ascribing contradictory beliefs to people feels uncharitable, and this could explain why many theorists have sought to avoid classifying delusions as beliefs.

This experiment pursues both of these speculations at once. On the one hand, we investigate whether the frequency of the Capgras patient's assertion affects whether people ascribe belief to him. On the other hand, we investigate whether Capgras patients are viewed as having contradictory beliefs. 


\subsection{Method}

Participants $(\mathrm{N}=202)^{7}$ were randomly assigned to one of eight conditions in a 2 (Frequency: Frequent, Infrequent) $\times$ Proposition (Impostor, Wife) $\times$ Probe (Believes, Thinks) betweensubjects design. All participants read a single story similar to the one used in Experiment 1.

The Frequency manipulation varied whether the protagonist asserted the delusional content regularly or only once in the story:

[Frequent/Infrequent]. Don and Katherine had been married for years. Like most married couples, they spent a lot of time together. They regularly shared meals, went to the movies, lived in the same house, and slept in the same bed. Then one day, as Don was driving to the store, a truck ran a stop-light and smashed into Don's car. Don suffered a traumatic brain injury in the accident. ๆ In the year following his injury, Don began a remarkable and speedy recovery. He regained his powers of speech, intelligence, and nearly all of his cognitive and social skills. One time, about a year after the accident, Don said to Katherine, "You are not my real wife. You are an impostor." [And that was the only time he said that. From then on, he never said it again./ But that was not the only time he said that. From then on, he said it every day.] I All the while, Don continued to always eat meals with Katherine, go to the movies her, live in the same house as her, and sleep in the same bed as her.

The Proposition manipulation varied which proposition we asked participants to focus on

${ }^{7}$ Fifty-five female, aged $18-59$ years, $\mathrm{M}=28.06, \mathrm{SD}=7.47 ; 98 \%$ reported English as a native language. 
when ascribing belief to Don. Participants in Impostor conditions were asked whether Don believes that Karen is an impostor. Participants in Wife conditions were asked whether Don believes that Karen is his wife. The purpose of this manipulation is to determine whether Capgras patients are readily viewed as having contradictory beliefs.

The Probe manipulation is similar to the one in Experiment 1. Participants in Believes conditions were asked to rate their agreement with the statement that Don "believes" a certain proposition is true. Participants in Thinks conditions were asked to rate their agreement with the statement that Don "thinks" a certain proposition is true. The motivation for this manipulation is two-fold. First, as already mentioned, prior results showed that when a protagonist verbally endorses a proposition, the effect on belief-ascription can depend on how one probes for beliefascription. Second, and relatedly, we again wanted to ensure that our results were not due to peculiarities associated with any one way of probing for belief-ascription.

Responses were collected on a standard 7-point Likert scale, anchored with "Strongly Disagree," "Disagree," "Somewhat Disagree," "Neutral," "Somewhat Agree," “Agree," and "Strongly Agree," left-to-right on the participant's screen, and coded "-3" through " 3 " for purposes of statistical analysis, creating a neutral midpoint of "0". (Participants never saw the numerical values, only the qualitative anchors.)

\subsection{Results}

An analysis of variance revealed a large-sized effect of condition on belief ascription, $F(7,194)=$ 
$7.96, \mathrm{p}<.000001, \eta \mathrm{p}^{2}=.223 .{ }^{8}$ There was a small-sized effect of Probe, with the "thinks" probe eliciting higher ascription than the "believes" probe $(\mathrm{M}=0.94 / 0.36, \mathrm{SD}=1.41 / 1.96), \mathrm{F}(1,194)$ $=7.97, \mathrm{p}=.005, \eta \mathrm{p}^{2}=.039$. There was a large-sized interaction of Frequency and Proposition, whereby the switch from Infrequent to Frequent raised rates of belief ascription in Impostor conditions but lowered them in Wife conditions, $\mathrm{F}(1,194)=40.81, \mathrm{p}<.000001, \eta \mathrm{p}^{2}=.174$. There was also a marginal small-sized main effect of Frequency, $F(1,914)=3.61, p=.059, \eta p^{2}$ $=.018$, and a marginal small-sized three-way interaction among Probe, Frequency, and Proposition, $\mathrm{F}(1)=2.985, \mathrm{p}=0.086, \eta \mathrm{p}^{2}=.015$. Figure 2 visualizes these results.

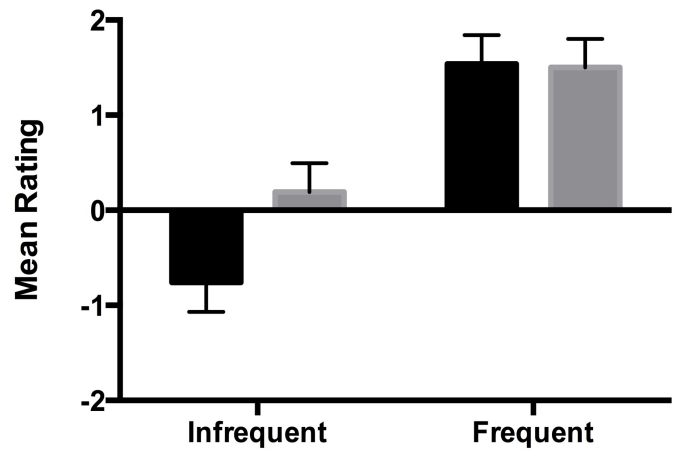

Imposter Belief

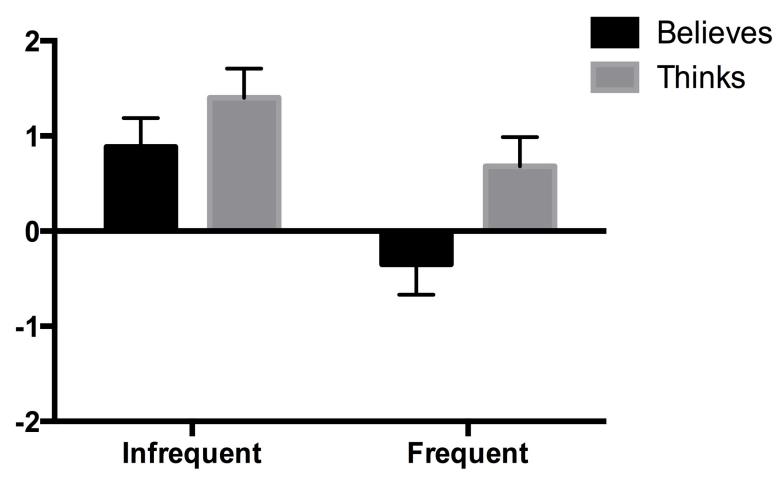

Wife Belief

\footnotetext{
${ }^{8}$ Partial-eta squared $\left(\eta p^{2}\right)$ is an effect size measure which indicates the amount of variance in a given dependent variable explained by a candidate independent variable. This measure delivers a value between 0 and 1. In interpreting $\eta p^{2}$ we follow Ellis [2010]. Thus, values greater than or equal to .14 are large, greater than or equal to .06 but less than .14 are medium, and greater than or equal to .01 but less than .06 are small.
} 
Fig. 2: Experiment 2. Mean belief ascription for the imposter belief (left) and wife belief (right) grouped by infrequent or frequent assertion. All scales ran (-3) to (+3). Error bars + one standard error of the mean.

We call attention to a range of relevant aspects of these results. First, when Don asserts only once that Katherine is an impostor, neither way of probing do participants ascribe to him the belief that Katherine is an impostor. One-sample t-tests show that the mean response to the "thinks" probe didn't differ significantly from the neutral midpoint, $\mathrm{M}=0.19, \mathrm{SD}=1.67, \mathrm{t}(25)=$ $0.586, \mathrm{p}=.563$. By contrast, the mean response to the "believes" probe was significantly below the midpoint, indicating the people tend to deny that Don believes that Katherine is an impostor, $\mathrm{M}=-0.76, \mathrm{SD}=1.54, \mathrm{t}(24)=-2.475, \mathrm{p}=.021$.

Second, when Don asserts only once that Katherine is an imposter, on both ways of probing, participants ascribe to him the belief that Katherine is his wife: "thinks," $\mathrm{M}=1.40, \mathrm{SD}$ $=0.957, \mathrm{t}(24)=7.311, \mathrm{p}<.000001 ;$ "believes," $\mathrm{M}=0.88, \mathrm{SD}=1.728, \mathrm{t}(25)=2.610, \mathrm{p}=.015$.

Third, when Don asserts every day that Katherine is an impostor, on both ways of probing participants ascribe to him the belief that Katherine is an impostor: "thinks," $\mathrm{M}=1.50, \mathrm{SD}=$ $1.105, \mathrm{t}(25)=6.925, \mathrm{p}<.000001$; "believes," $\mathrm{M}=1.54, \mathrm{SD}=1.334, \mathrm{t}(25)=5.882, \mathrm{p}<.00001$.

Fourth, when Don asserts every day that Katherine is an impostor, the "thinks" and "believes" probes elicit significantly different responses in Wife conditions. When asked whether they agree that Don thinks that Katherine is his wife, the mean response is significantly above the neutral midpoint, $\mathrm{M}=0.68, \mathrm{SD}=1.406, \mathrm{t}(24)=2.418, \mathrm{p}=.024$. By contrast, when asked whether they agree that Don believes that Katherine is his wife, the mean response is below the 
midpoint, though not significantly so, $\mathrm{M}=-0.35, \mathrm{t}(22)=-0.723, \mathrm{p}=.477$.

On the ordinary way of evaluating the case, then, we may conclude the following about Don's case. In light of Don's isolated assertion that Katherine is an impostor:

- it's unclear whether he thinks that she is an impostor;

- he doesn't believe that she is an impostor;

- he definitely thinks that she is his wife; and

- he believes that she is his wife.

By contrast, in light of Don's daily assertions that Katherine is an impostor:

- he definitely thinks that she is an impostor;

- he definitely believes that she is an impostor;

- he thinks that she is his wife; but

- it's unclear whether he believes that she is his wife.

Fifth, and most importantly, it follows from what we've already said that people tend to ascribe contradictory attitudes to a prototypical Capgras patient. More specifically, when Don regularly asserts that Katherine is an impostor, people agree both that he thinks that Katherine is an impostor and that he thinks that Katherine is his wife.

Sixth, compounding the fact that people tend to agree that Don thinks contradictory claims are true, they also view Don as "thinking" something is true without also "believing" it. More specifically, they view him as thinking it's true that Katherine is his wife, but they do not view him as believing that she is his wife. In light of this serious, compound tension, it's perfectly understandable that some theorists would consider revising aspects of the ordinary ways of viewing such cases. In particular, it's understandable that they would consider denying 
that Don thinks that both of these things are true, and then pick one of them to reject. Ironically, however, these theorists end up rejecting that Don thinks Katherine is an impostor, whereas ordinarily people think it's much clearer that Don thinks she is an impostor than that he thinks she's his wife.

Seventh, the results in Frequent conditions demonstrate the surprising power that assertion has in eliciting belief ascription. Consider all the non-verbal behavior which is well explained by ascribing to Don the belief that Katherine is his wife: he always eats meals with her, goes out with her, lives with her, and sleeps in the same bed as her. When it comes to eliciting belief-ascription, this persistent and robust profile of non-verbal behavior pales in comparison to the power of circumscribed but consistent verbal behavior. All Don has to do is to say daily, "You are an impostor," and people overwhelmingly ascribe to him the relevant belief. Despite the old adage, "Actions speak louder than words," when it comes to belief, it seems that words can sometimes speak far louder than actions. To swap one adage for another, in evaluating what others believe, "the tongue is mightier than the sword."

Finally, the pattern of results suggests that if you "believe" that something is true, then you "think" that it is true. But the converse does not hold: if you "think" that something is true, it's still an open question whether you also "believe" that it is true. This replicates and generalizes previous findings, in which the "thinks" probe elicited significantly higher rates of ascription than the "believes" probe [Buckwalter, Rose and Turri 2013; Buckwalter and Turri 2014]. 


\subsection{Discussion}

The results from this experiment support two main conclusions. First, the frequency of a Capgras patient's assertion affects whether people ascribe belief to him. Second, Capgras patients are viewed as having contradictory beliefs.

\section{Experiment 3: Strength from Within}

The results from Experiment 2 suggest an explanation for why folk psychology recognizes cases of Capgras delusion as instances of stereotypical belief: frequent assertion is a powerful cue to belief ascription. That is, a pattern of frequent assertion is stereotypically associated with belief. Experiment 2 also provided support for the claim that, on the ordinary way of viewing matters, paradigmatic Capgras patients have contradictory beliefs. Participants tended to view Don as both thinking that Katherine is his wife and thinking that she is an impostor. However, we used a between-subjects design, so no one participant ascribed both of those beliefs to Don. Even better evidence for a tendency toward contradictory ascription would come from individual participants ascribing both beliefs together, as opposed to different groups of participants ascribing each belief separately. This experiment follows up on this suggestion.

\subsection{Method}

Participants $(\mathrm{N}=55)^{9}$ were randomly assigned to one of two groups, Believes and Thinks. All participants read the Frequent story from Experiment 2 (i.e. the prototypical Capgras case where

\footnotetext{
${ }^{9}$ Twenty female, aged $18-60, \mathrm{M}=31, \mathrm{SD}=10.15 ; 91 \%$ reported English as a native language.
} 
Don frequently asserts that Katherine is an impostor). The between-subjects factor was the probe used; it was the same probe manipulation used in Experiments 1 and 2. The within-subjects factor was that all participants were asked to rate their agreement with both of the relevant statements, namely, that Don believes/thinks Katherine is his wife, and that Don believes/thinks Katherine is an impostor. Otherwise, the procedure was the same as in Experiment 2.

\subsection{Results}

The main question is whether participants would continue to ascribe contradictory beliefs to Don. It turns out that they did. In the Thinks condition, mean agreement with both ascriptions was significantly above the neutral midpoint: Wife, $\mathrm{M}=0.70, \mathrm{SD}=1.35, \mathrm{t}(26)=2.702, \mathrm{p}=.012$; Impostor, $\mathrm{M}=1.63, \mathrm{SD}=1.33, \mathrm{t}(26)=6.346, \mathrm{p}<.00001$. In the Believes condition, mean agreement with the Impostor ascription was significantly above the neutral midpoint, $\mathrm{M}=0.96$, $\mathrm{SD}=1.89, \mathrm{t}(27)=2.693, \mathrm{p}=.012$, whereas mean agreement with the Wife ascription was nonsignificantly below the midpoint, $\mathrm{M}=-0.50, \mathrm{SD}=1.89, \mathrm{t}(27)=-1.396, \mathrm{p}=.174$. Figure 3 visualizes these results. 


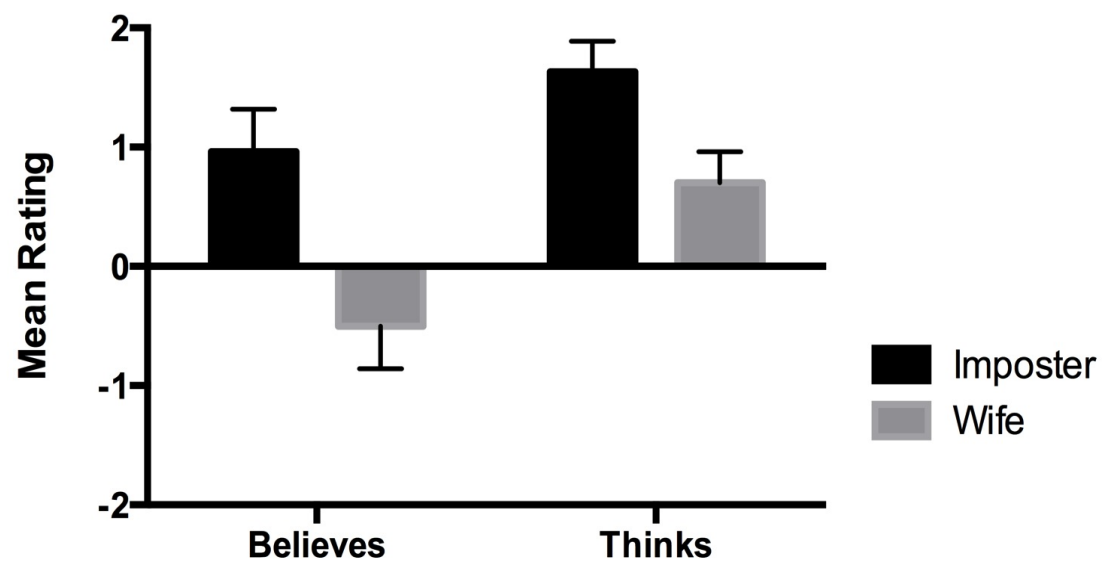

Fig. 3: Experiment 3. Mean imposter and wife belief ratings grouped by the two belief probes presented within-subjects to each participant. All scales ran $(-3)$ to $(+3)$. Error bars + one standard error of the mean.

\subsection{Discussion}

Even when using a within-subjects design, we continue to find that participants attribute the belief to Don that his wife is an imposter. And, importantly, we continue to find that people indeed the same individuals — are willing to ascribe contradictory attitudes to Don, namely, that he both thinks that Katherine is an imposter and thinks that she is his wife.

\section{Experiment 4: A Figment of Imagination?}

Experiments 1-3 provided evidence that folk psychology recognizes cases of monothematic delusions as stereotypical beliefs. But at least two objections arise at this point. The first objection is that at least some participants might be ascribing belief due to pragmatic pressures 
associated with principles of charity rather than features stereotypically associated with belief. That is, they might answer that Don believes (thinks) that Katherine is an impostor because they think he should believe this. The second objection is that at least some of the belief-ascription we observed was an artifact of the way we questioned participants. Some participants might ascribe belief because it's the best available option, not because they really accept that Don believes that the claim in question is true. In all of our studies, we asked whether the Capgras patient believes or thinks that his wife is an imposter, but we did not compare these ascriptions to judgments about other mental states debated in the philosophical literature on delusional contents, such as

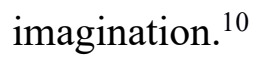

This experiment was designed to address these objections. On the one hand, we investigate whether people think Capgras patients should believe the content of their delusions. On the other hand, we contrast belief ascription with another rival attitude advocated in the delusional literature: imagination.

\subsection{Method}

Participants $(\mathrm{N}=137)^{11}$ read the Frequent story from Experiment 2 (i.e. the prototypical Capgras case). They were randomly assigned to one of two conditions, Thinks Contrast or Believes Contrast, distinguished by the contrasts featured in the probe with imagination. In the Thinks condition, participants were asked which better describes the case:

\footnotetext{
${ }^{10}$ We thank Maura Tumulty for helpful discussion on this point.

${ }^{11}$ Fifty-eight female, aged $18-62$ years, $\mathrm{M}=31.6, \mathrm{SD}=10.54 ; 93 \%$ reported English as a native language.
} 
Thinks Contrast. Don that Katherine is an impostor. [at least on some

level thinks/is just imagining]

In the Believes condition, participants were given the same open sentence, but had different options:

\section{Believes Contrast. Don _ that Katherine is an impostor. [actually believes/just imagines]}

Answers to both of these questions were collected on a dichotomous, forced choice scale. The order of answer choices randomized. Finally, in both conditions, participants then advanced to a new screen and responded to an open probe:

Should Control. Given his evidence, Don believe/think that Katherine is an impostor.

Responses were collected on a 6-point scale with anchors ranging from "Definitely shouldn't" to "Definitely should," with no neutral midpoint. Participants could not return to previous screens to change their answers.

\subsection{Results}

We made two predictions. First, when "imagines" is explicitly contrasted with "thinks" or "believes," participants will still continue to ascribe belief. Second, participants will answer that the patient should not believe or think that Katherine is an imposter.

Both predictions were true. Despite having the opportunity to describe Don's attitude in terms of imagining, participants continued to attribute beliefs to Don at rates significantly 
exceeding chance. In the Thinks condition, the majority of participants (90\%) chose "thinks" over "imagines," binomial test, $\mathrm{p}<.000001$. In the Believes condition the majority $(63 \%)$ of participants chose "believes" over "imagines," binomial test, $p<.05 .{ }^{12}$ Figure 4 visualizes the results. We also found that participants overwhelmingly said that Don should not believe or think that his wife is an imposter $(\mathrm{M}=1.87, \mathrm{SD}=0.91), \mathrm{t}(136)=-21.1, \mathrm{p}<.000001$.

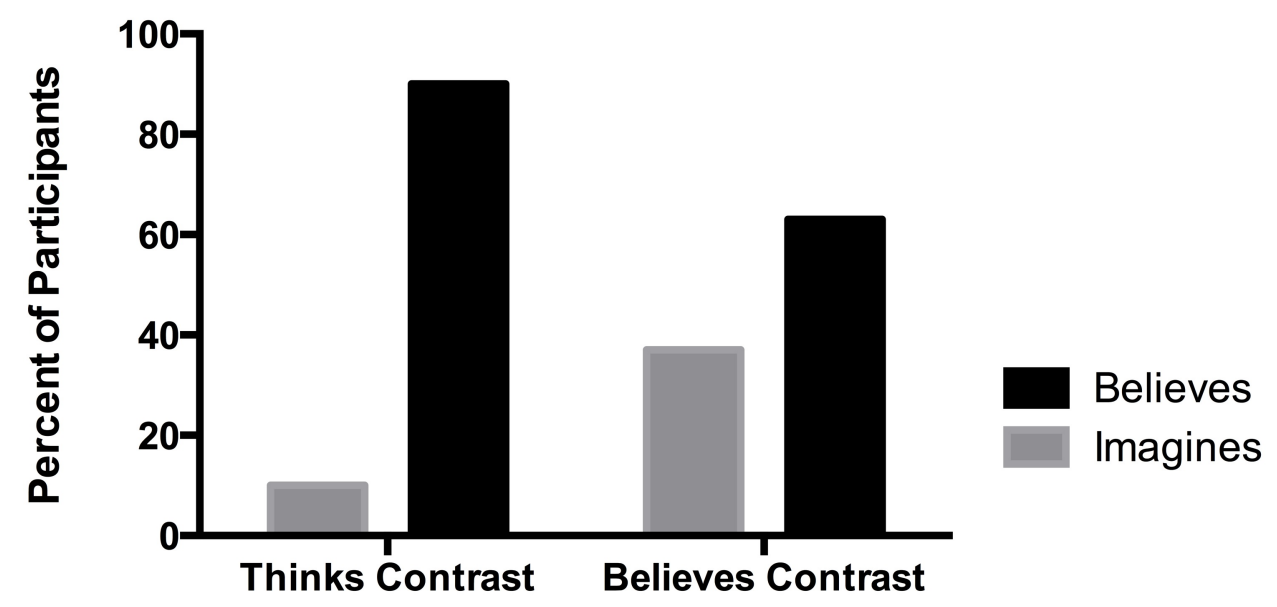

${ }^{12}$ We also found a statistically significant medium-sized effect of probe on answers to the test question, whereby 'thinks' more so than 'believes' was chosen over 'imagines', $\chi^{2}=13.34, p<.001$, Cramer's $\mathrm{V}=$ .312. Cramer's V is a non-parametric correlation coefficient that indicates the strength of correlation between nominal variables. We follow Ellis [2010] for interpreting magnitudes of effect sizes using this measure. This finding further supports the arguments presented in Buckwalter, Rose and Turri 2013, regarding the distinction between "thick" and "thin" belief. 
Fig. 4: Experiment 4. Percentage of participants ascribing belief (at least on some level thinks/actually believes) or imagination grouped by Thinks Contrast and Believes Contrast conditions.

\subsection{Discussion}

These findings replicate our previous results suggesting that folk psychology recognizes cases of monothematic delusion as cases of belief. They also show that belief-ascription in these cases isn't due to charity or the unavailability of other options.

\section{Experiment 5: Generality and Reaction Time}

In this final experiment, we address three natural concerns about our findings thus far. ${ }^{13}$ First, although frequent assertion affects rates of belief ascription to delusional patients in these cases, perhaps frequent assertion would not influence rates of belief ascription to non-delusional subjects. Second, although people attribute belief at high rates to delusional patients, people might do so only reluctantly. If either of these things were true, it would suggest that delusions are still somewhat atypical beliefs. Third, we have only tested cases involving Capgras delusions. Perhaps other monothematic delusions are viewed differently. We will address these concerns by comparing a delusional agent to a non-delusional agent, collecting reaction-time data, and focusing on a different type of delusion (in this case, Fregoli). Collecting reaction times will allow us to determine whether people take significantly longer to decide in delusional cases.

\footnotetext{
${ }^{13}$ We would like to thank two anonymous referees for raising these points.
} 
Research in cognitive psychology shows that atypicality affects performance by increasing the time people take to complete categorization tasks [Smith and Kosslyn 2007: 179; see also Rosch 1975].

\subsection{Method}

Participants $(\mathrm{N}=120)^{14}$ were randomly assigned to one of four conditions, in a 2 (Mentality: Passionate, Delusional) $\times 2$ (Frequency: Once, Daily) between-subjects design.

Don works in a large office building. He also has a rare [passion for mystery novels/delusional psychiatric disorder] that can cause strange behavior. For instance, one day, Don tells his boss, "You look just like a normal citizen, but you're really a foreign spy, working on a secret mission." [And/But] that [was/was not] the only time Don said that. From then on, he [never said it again/said it every day].

Participants then rated their agreement or disagreement with the following statement, on the same 7-point scale used in Experiment 2: "Don believes that his boss is a spy." To ensure that our Mentality manipulation was effective, we included the following manipulation check, which was presented on a separate screen: "Don has a rare .$"$ (passion for novels/psychiatric disorder).

\subsection{Results}

The manipulation was extremely effective, with over $90 \%$ of participants responding as

${ }^{14}$ Forty-seven female, aged $18-64$ years, $\mathrm{M}=30.47, \mathrm{SD}=10.55 ; 96 \%$ reported English as a native language. 
predicted. Planned comparisons indicated that Frequency affected belief attribution for both the Delusional (Once/Daily, $\mathrm{M}=3.53 / 5.43, \mathrm{SD}=1.78 / 1.78, \mathrm{t}(58)=4.15, \mathrm{p}=.000)$ and Passionate cases (Once/Daily, $\mathrm{M}=3.37 / 4.27, \mathrm{SD}=1.56 / 1.80, \mathrm{t}(58)=2.07, \mathrm{p}=.043)$. And planned comparisons indicated that reaction times did not significantly differ between the Delusional (M $=11.35$ seconds, $\mathrm{SD}=8.04)$ and Passionate cases $(\mathrm{M}=10.74$ seconds, $\mathrm{SD}=6.50), \mathrm{t}(118)=.451$, $\mathrm{p}=.653$.

\subsection{Discussion}

The present results address all three concerns mentioned in the introduction to this experiment. We observed that frequency of assertion affects belief-ascription in delusional and nondelusional cases alike. And we observed that frequency of assertion affects belief-ascription for a different monothematic delusion. Finally, the reaction-time data undermine the suggestion that people attribute belief in delusional cases only reluctantly.

\section{Conclusions}

Do delusional patients believe the content of their delusions? The folk psychology of belief has played a large role in recent attempts to answer this question. Some theorists answer "no"; others offer a qualified "yes", suggesting that if delusions are characterized as beliefs then delusions are "anomalous beliefs," or that they are beliefs in some contexts but not others [Reimer 2010], or that they aren't "fully" beliefs because they don't "fully meet any relevant folk-psychological stereotype" for belief [Tumulty 2012: 30, n. 2; see also Schwitzgebel 2011; Schwitzgebel 2001]. 
Even among theorists who otherwise disagree deeply over monothematic delusions, there is widespread agreement that delusions don't fit the functional profile of belief [Bayne 2010: $330] \cdot{ }^{15}$

For a debate largely centered on the folk psychology of belief, it is surprising that there has been no empirical investigation of the folk practice of belief ascription in cases of delusion. We sought to rectify this, suspecting that both sides were wrong to assume that delusions were anything other than uncontroversial cases of belief. To test this suspicion, we conducted a series of experiments to measure how people ordinarily view cases involving such delusions.

The results show that our suspicion hit the mark. It turns out that monothematic delusions are overwhelmingly viewed as beliefs (Experiment 1). Rates of belief ascription were at or near ceiling, strongly suggesting that, at least on the ordinary way of thinking, these delusions are not only beliefs, but stereotypical beliefs. They fit at least one stereotypical profile for belief.

But what profile might that be? It turns out that the delusional patient's verbal behavior is a powerful cue to belief ascription (Experiment 2). In folk psychology, persistent assertion cues belief-ascription. Surprisingly, for participants in our studies, a persistent pattern of assertion was a much stronger cue to belief-ascription than a robust and consistent profile of non-verbal behavior was. Apparently, in folk psychology, words speak louder than actions. Or perhaps the way to put it is this: speech acts are the loudest actions of all. ${ }^{16}$ This finding coheres with previous work in experimental philosophy [Buckwalter, Rose and Turri 2013] and developmental

${ }^{15}$ For more on functionalism in folk psychology and the metaphysics of mind, see Buckwalter and Phelan 2013; Buckwalter and Phelan forthcoming.

${ }^{16}$ Or in a memorable slogan offered by one of the authors' fathers, "words may die inside your head, but even god can't erase what's been said." 
psychology [Roth and Leslie 1991; see also Nichols and Stich 2003], which suggests that assertion is a powerful cue to belief ascription.

We also investigated whether delusional patients were ordinarily viewed as having contradictory beliefs. Across two studies, participants tended to ascribe contradictory beliefs. We observed this result both between-subjects (Experiment 2) and within-subjects (Experiment 3). We provided evidence that, when given other ways to describe the delusional patient's attitudes (e.g. as imaginings), participants continue to prefer to describe them in terms of belief (Experiment 4). Finally, we showed that our basic findings aren't limited to one particular type of delusion and extend even to non-delusional cases; moreover, based on reaction times, it does not appear that people hesitantly or reluctantly attribute belief to delusional agents (Experiment $5)$.

While our results suggest that the folk view cases of monothematic delusions as stereotypical beliefs, we acknowledge that some researchers engage in viable projects that might permit them to disconnect from the folk psychology of belief and characterize delusions differently. For instance, some philosophers might be engaged in normative projects arguing that the folk are wrong to characterize stereotypical beliefs in the ways we have uncovered. And some cognitive scientists might focus on investigating the cognitive or neurological processes that underwrite instances of delusion, where this is divorced from folk psychology entirely [see Blackwood et al. 2001; Gerrans 2013]. Our focus has only been on the ordinary concept of belief in relation to instances of delusion and so the present study is not intended to discredit or even dispute such prescriptive or revisionary projects concerning the folk psychology of belief or projects aimed at understanding the underlying cognitive processes involved in delusion. 
Our results are relevant to those with prescriptive or revisionary tendencies. After all, an adequate empirical understanding of the folk psychology of belief is a precondition for determining whether to prescribe better practices, or whether a proposal counts as revisionary in the first place. Beyond this, it's important to understand folk psychology because it enables significant success in predicting and explaining the behavior of others [Kitcher 1984; Fodor 1987; Lahav 1992]. This considerable success in turn provides a baseline standard against which revisionist theories can be measured. We tend to favor the conservative view that significant divergence from folk psychology is a noteworthy, though not necessarily prohibitive, cost of a theory. But it's not our purpose to defend that stance here and neither our findings nor our interpretation of them depends on it. ${ }^{17}$

\author{
David Rose \\ Department of Philosophy \\ Rutgers University \\ Wesley Buckwalter \\ Department of Philosophy \\ University of Waterloo \\ John Turri \\ Department of Philosophy \\ University of Waterloo
}

${ }^{17}$ We would like to thank Carolyn Buckwalter, John Buckwalter, Lisa Bortolotti, Richard Dub, Dan Greco, Joshua Knobe, Shaun Nichols, Eric Schwitzgebel, Maura Tumulty, Angelo Turri and two anonymous referees for helpful feedback on earlier drafts of this paper. This research was supported by the Social Sciences and Humanities Research Council of Canada and an Ontario Early Researcher Award. 


\section{REFERENCES}

Alexander, M.P., D.T. Stuss and D.F. Benson 1979. Capgras' Syndrome: A Reduplicative Phenomenon, Neurology 29/3: 334-339.

American Psychiatric Association2000. Diagnostic and Statistical Manual of Mental Disorders (4 ed.). American Psychiatric Publishing.

Bayne, T. 2010. Delusions as Doxastic States: Contexts, Compartments, and Commitments, Philosophy, Psychiatry, and Psychology 17/4: 329-336

Blackwood, N.J., R.J. Howard, R.P. Bentall and R.M. Murray2001. Cognitive Neuropsychiatric Models of Persecutory Delusions, American Journal of Psychiatry 158/4: 527-539.

Bortolotti, L. 2012. In Defense of Modest Doxasticism About Delusions, Neuroethics 5/1: 39-53.

Bortolotti, L. and M. Mameli 2012. Self-deception, Delusion and the Boundaries of Folk Psychology, Humana.Mente 20: 203-221.

Buckwalter, W., D. Rose and J. Turri 2013. Belief through Thick and Thin, Nous doi: $10.1111 /$ nous.12048.

Buckwalter, W., and J. Turri 2014. In the Thick of Moral Motivation, Working Paper Series. Available at SSRN: http://ssrn.com/abstract=2382383. Accessed on January 20, 2014.

Buckwalter, W., and M. Phelan 2013. Function and Feeling Machines: A Defense of the Philosophical Conception of Subjective Experience, Philosophical Studies 166/2: 349361.

Buckwalter, W., and M. Phelan forthcoming. Phenomenal Consciousness Disembodied, in Advances in Experimental Philosophy of Mind, ed. Justin Sytsma, Bloomsbury. 
Cermolacce, M., L. Sass and J. Parnas 2010. What is Bizarre in Bizarre Delusions? A Critical Review, Schizophrenia Bulletin 6/4: 667-679.

Coltheart, M. 2007. Cognitive Neuropsychiatry and Delusional Belief, The Quarterly Journal of Experimental Psychology 60/8: 1041- 1062.

Currie, G. 2000. Imagination, Delusion and Hallucinations, in Pathologies of Belief, eds. Max Coltheart and Martin Davies, Blackwell.

Currie, G. and J. Jureidini 2001. Delusion, Rationality, Empathy, Philosophy, Psychiatry and Psychology 8/2-3:159-62.

Currie, G. and I. Ravenscroft 2002. Recreative Minds: Imagination in Philosophy and Psychology. Oxford University Press.

Davidson. D. 1982. Paradoxes of Irrationality, in Philosophical essays on Freud, eds. Richard Wollheim and James Hopkins, Cambridge: Cambridge University Press: 289-305.

Davidson, D. 1986. Deception and Division, in The Multiple Self, ed. Jon Elster, Cambridge: Cambridge University Press: 79- 92.

Egan, A. 2009. Imagination, Delusion, and Self-deception, in Delusions, Self-deception, and Affective Influences on Belief Formation, eds. Tim Bayne and Jordi Fernandez, Psychology Press: 263-279.

Ellis, Paul 2010. The Essential Guide to Effect Sizes: Statistical Power, Meta-Analysis and the Interpretation of Research Results. Cambridge University Press.

Fodor, J. 1987. Psychosemantics. Cambridge, MA: MIT Press.

Frankish, K. 2012. Delusions, Levels of Belief, and Non-doxastic Acceptances, Neuroethics 5/1: $23-27$. 
Gerrans, P. 2013. Delusional Attitudes and Default Thinking, Mind and Language doi: 10.1111/mila.12010.

Gendler, T. S. 2007. Self-deception as Pretense, Philosophical perspectives 21/1: 231-258.

Hirstein, W., and V.S. Ramachandran (1997. Capgras syndrome: a novel probe for understanding the neural representation of the identity and familiarity of persons, Proceedings of the. Royal Society of London B264: 437-44.

Hohwy, J., and V. Rajan 2012. Delusions as Forensically Disturbing Perceptual Inferences, Neuroethics 5/1: 5-11.

Jaspers, K. 1963. General Psychopathology (translated from German by J. Hoenig and M.W. Hamilton). Manchester: Manchester University Press.

Kitcher, P. S. 1984. In Defense of Intentional Psychology, Journal of Philosophy 81/2: 89-106.

Lahav, R. 1992. The Amazing Predictive Power of Folk Psychology, Australasian Journal of Philosophy 70/1: 99-105.

Murphy, D. 2012. The Folk Epistemology of Delusions, Neuroethics 5/1: 19-22.

Nichols, S. and S. Stich. 2003. Mindreading: An Integrated Account of Pretense, Self-Awareness and Understanding Other Minds. Oxford University Press.

Parnas J. 2004. Belief and Pathology of Self-awareness: A Phenomenological Contribution to the Classification of Delusions, Journal of Consciousness Studies 11/10-11:148-161.

Reimer, M. 2010. Only a Philosopher or a Madman: Impractical Delusions in Philosophy and Psychiatry, Philosophy, Psychiatry, and Psychology 17/4: 315-328.

Rosch, E. 1975. Cognitive Representations of Semantic Categories, Journal of Experimental Psychology: General, 104/3: 192-233. 
Rose, D. and J. Schaffer 2013. Knowledge Entails Dispositional Belief, Philosophical Studies 166/1: 19-50.

Roth, D., and A.M. Leslie 1991. The Recognition of Attitude Conveyed by Utterance: A Study of Preschool and Autistic Children, British Journal of Developmental Psychology 9/2: $315-330$.

Schwitzgebel, E.2001. In-between Believing, The Philosophical Quarterly 51/202: 76-82.

Schwitzgebel, E2011. Mad Belief? Neuroethics, 5/1: 13-17.

Smith, E. E., and S.M. Kosslyn 2006. Cognitive Psychology: Mind and Brain. Pearson.

Tumulty, M. 2012. Delusions and Not-Quite-Beliefs, Neuroethics 5/1: 29-37.

Wimmer, H., \& J. Perner 1983. Beliefs About Beliefs: Representation and the Containing Function of Wrong Beliefs in Young Children's Understanding of Deception, Cognition 13/1: 103-128. 